\title{
Feeling the heat
}

\author{
Drought and heatwaves are inextricably linked, and have devastating socio-economic and environmental impacts. \\ This issue features a suite of articles outlining how these extreme events may increase in magnitude and frequency \\ with anthropogenic warming, highlighting the increased need to mitigate and adapt to future conditions.
}

W hile a far cry from the bitter cold that left much of Europe and North America shivering in recent months, a remarkable number of devastating heatwaves have been observed in recent years. In the summer of 2003, temperatures soared up to $5{ }^{\circ} \mathrm{C}$ ( 5 standard deviations) above normal across Western Europe ${ }^{1}$, with extreme heat also scorching Russia during 2010, North America in 2012, Australia during the 'Angry Summer' of 2012/2013 and China in 2013. Examples are too numerous to comprehensively list, but they all have one thing in common: devastating impacts on both human and natural systems. Indeed, the cases highlighted above all resulted in numerous heat-related deaths ${ }^{2}$. For instance, upwards of 30,000 and 55,000 people died from the 2003 and 2010 heatwaves, respectively. Increased energy demand, wildfires, ecosystem shifts and reduced agricultural yield and gross primary production (which both transform ecosystems from carbon sinks to sources) further epitomize heatwave impacts.

Although anthropogenic climate change is often characterized through increased global mean temperature, some of the most pervasive changes have been in extreme heat. There has been an increase in the frequency, duration and magnitude of heatwaves around the globe ${ }^{3}$, a trend that is set to continue $e^{4}$. In this issue, for example, Shingirai Nangombe and colleagues propose that heatwaves in Africa - specifically those akin to the 2009/2010 event in north Africa and the 2015 continent-wide event, both of which set new daily maximum temperature records - will become increasingly frequent in the future, highlighting greater risk to an already vulnerable continent.

While there is overall consensus that heatwaves will become more commonplace, there has been difficulty in determining when anthropogenically forced heatwaves (those that would not have occurred in the absence of rising $\mathrm{CO}_{2}$ concentrations) will emerge against natural variability. Focusing on the United States, Hosmay Lopez and co-authors reveal that human-forced heatwaves will first appear in the western United States (California and Nevada) and Great Lakes (Minnesota, Iowa, Wisconsin,
Illinois) - regions that are already suffering record-breaking heat - by 2020-2030.

However, anthropogenic warming has not only worsened heatwaves. Warmer temperatures have also increased evaporative demand, which alongside concurrent shifts in precipitation, has exacerbated the intensity and impact of droughts. Like heatwaves, droughts have garnered significant media attention in recent years due to their apparent rising propensity, as evidenced by the situation in California during 2012-2016 and the ongoing event in Cape Town, where Day Zero looms (see Snapshot in this issue). Nevertheless, climate change is not anticipated to create droughts, rather to amplify existing conditions ${ }^{5}$. Luis Samaniego and colleagues, for example, suggest that under $3^{\circ} \mathrm{C}$ of warming - which is expected with present-day commitments to reduce GHG emissions - soil moisture deficits observed during the 2003 European heatwave will be twice as frequent and very much the norm in the future. Thus, with present-day extremes no longer representative of deviations from normal conditions, they propose that the definition of drought may need to be reassessed to incorporate their changing characteristics. Daniel Swain and co-workers additionally reveal that the frequency of extremely dry years will increase across California, but that increases in consecutive dry years are only anticipated for southern California by the end of the twenty-first century.

Drought and heatwaves, however, are inextricably linked, and it is often difficult to treat them as distinct phenomena. As discussed above, warmer temperatures (during heatwaves, for example) enhance evaporation and amplify drought conditions. But the converse is also true. Drought conditions can enhance or dampen heatwave temperatures, as Lucinda Rasmijn and co-authors discuss. During periods of higher soil moisture, maximum heatwave temperatures are capped, as incoming solar energy is balanced by evaporative cooling (the latent heat flux) rather than the ground radiating heat (the sensible heat flux), which raises surface temperature. In the future, Rasmijn et al. demonstrate that a loss of soil moisture (representative of increased drought) will modify the balance between the latent and sensible heat fluxes, and in the case of an event analogous to the 2010 Russia heatwave, maximum temperatures could be amplified by $8^{\circ} \mathrm{C}$.

It is clear from these studies that heatwaves and associated droughts will become more common and stronger in the future. Yet with global efforts to constrain anthropogenic warming to $1.5^{\circ} \mathrm{C}$ above preindustrial temperatures, questions have arisen regarding the potential to mitigate such increases. Several articles in this issue reveal the benefits of limiting warming to $1.5^{\circ} \mathrm{C}$ instead of $2{ }^{\circ} \mathrm{C}$ for heat-related extreme events: Samaniego et al. highlight that the area of Europe exhibiting soil moisture drought is significantly reduced, with a corresponding decline in the population exposed to such conditions; and Nangombe et al. demonstrate a $20 \%$ decrease in the likelihood of extreme heatwaves and droughts in Africa, consistent with previous studies performed for Australia ${ }^{6}$.

With the immense socio-economic and environmental impacts of droughts and heatwaves, nations will need to adapt to their increased occurrence and magnitude, regardless of whether warming is limited to $1.5^{\circ} \mathrm{C}$ or $2{ }^{\circ} \mathrm{C}$. Any increase in the severity of hydroclimatic extremes threatens mortality, water resources (as seen in Cape Town), or water infrastructure (as seen in California). Although the research outlined in this issue - and in an accompanying online collection www.nature.com/collections/ drought - advances our understanding, more work is needed to mitigate against and adapt to an almost inevitable increase in heatwaves and drought.

Published online: 27 April 2018 https://doi.org/10.1038/s41558-018-0169-y

\footnotetext{
References

1. Schär, C. et al. Nature 427, 332-336 (2004)

2. Mora, C. et al. Nat. Clim. Change 7, 501-506 (2017)

3. Perkins, S. E., Alexander, L. V. \& Nairn, J. R. Geophys. Res. Lett. 39, L20714 (2012).

4. Meehl, G. A. \& Tebaldi, C. Science 305, 994-997 (2004).

5. Trenberth, K. E. et al. Nat. Clim. Change 4, 17-22 (2014).

6. King, A. D., Karoly, D. J. \& Henley, B. J. Nat. Clim. Change 7, 412-416 (2017).
} 